\title{
A REVIEW OF STUDY AND ANALYSIS OF PARTIAL DISCHARGE FOR DIFFERENT INSULATION MATERIALS WITH CAPACITANCE VALUE
}

\author{
Neetu Baghelkar ${ }^{1}{ }^{凶}$, Prof. Abhishek Dubey ${ }^{2}$ \\ ${ }^{1}$ M. Tech Student (Power System), Bhopal Institute of Technology \& Science, Bhopal (M.P.), India \\ 2 Professor, Bhopal Institute of Technology \& Science, Bhopal (M.P.), India
}

DOI: https://doi.org/10.29121/ijetmr.v7.i12.2020.844

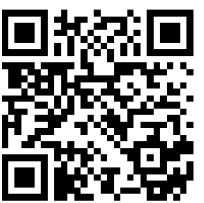

Article Citation: Neetu Baghelkar, and Prof. Abhishek Dubey. (2020). A REVIEW OF STUDY AND ANALYSIS OF PARTIAL DISCHARGE FOR DIFFERENT INSULATION MATERIALS WITH CAPACITANCE VALUE. International Journal of Engineering Technologies and Management Research, 7(12), 6466.

https://doi.org/10.29121/ijetmr.v7 i12.2020.844

Published Date: 31 December 2020

Keywords:

Partial Discharge

Insulation Materials

Capacitance Value

\section{ABSTRACT}

In the high voltage (HV) electrical power system, a variety of solid, liquid and gaseous materials are used for insulation purposes to protect incipient faults within the HV power equipment. Among these, solid insulation is widely used for high voltage equipment in high voltage power systems. Most insulation materials are not perfect in all respects and always contain some impurities. In high voltage (HV) electrical equipment, the quality of the insulation plays a very important role. Continued growth in the power system has provided the opportunity to protect equipment for healthy operation throughout its useful life.

\section{INTRODUCTION}

Insulation faults arise from the presence of partial discharges in high-voltage power equipment. Due to partial discharges, the properties of such insulators deteriorate enormously. Therefore, controlling high voltage insulation and safe handling is the most important priority of power engineers to keep high voltage power equipment in healthy condition. Partial discharges are always caused by a poor and empty conductor profile in high voltage equipment. Because of the above, describe the reasons why partial discharge detection and measurement is necessary to predict damage to equipment insulation and ensure long-term operation of high-voltage electrical equipment. In most highvoltage (HV) equipment, the equipment is made of different types of high-quality insulation to protect against highvoltage trees.

Due to degradation of insulation material in power system equipment, other equipment tends to be less efficient. In high voltage power equipment, different types of materials such as solid, gaseous and liquid and a combination of those materials are used for insulation purposes. In this work, we are studying and analyzing partial discharges for different types of insulating materials.

A variety of solids, gases, liquids, and combinations of these materials are used as insulation in high-voltage equipment. Among them, solid insulation, such as epoxy resin, is widely used, not only as a component of complex insulation systems, such as the insulation of rotating HV machines, but also in internal insulators, transformers, and various high-voltage equipment. Accessing the quality of this insulation is a challenging task for power engineers,

(c) 2020 The Author(s). This is an open access article distributed under the terms of the Creative Commons Attribution License, which permits unrestricted use, distribution, and reproduction in any medium, provided the original author and source are credited. 
while the same power equipment has been operating under high voltage for a long time. The quality of such insulation plays an important role in high-voltage power equipment in quality assessment.

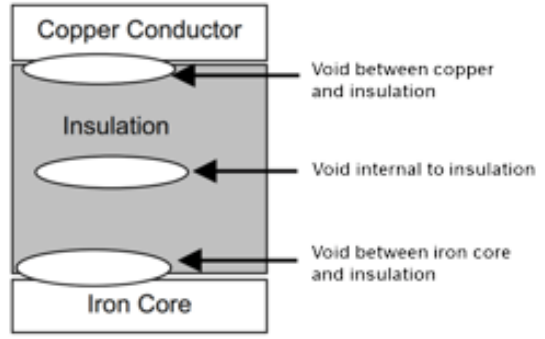

Figure 1: Partial discharge in void

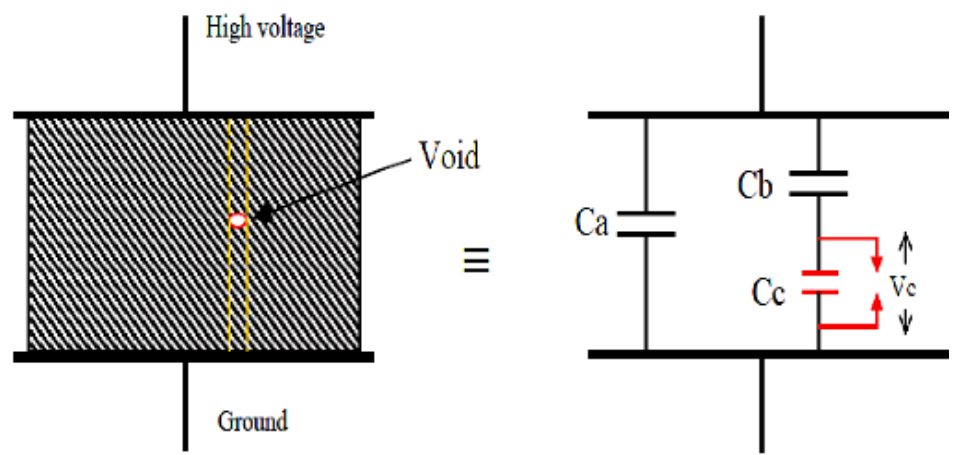

Figure 2: Capacitance model in solid insulation

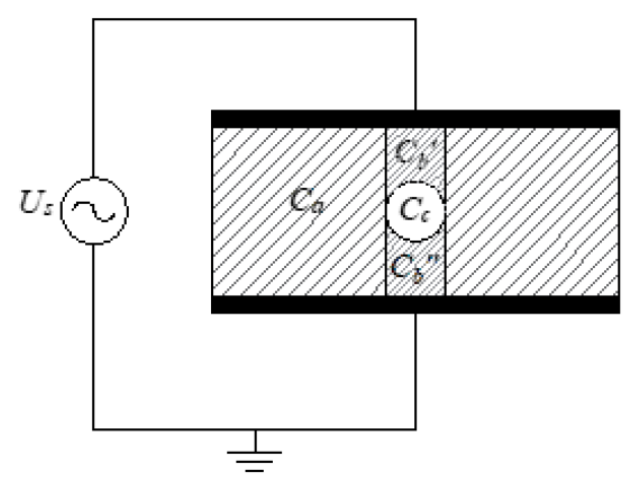

(a)

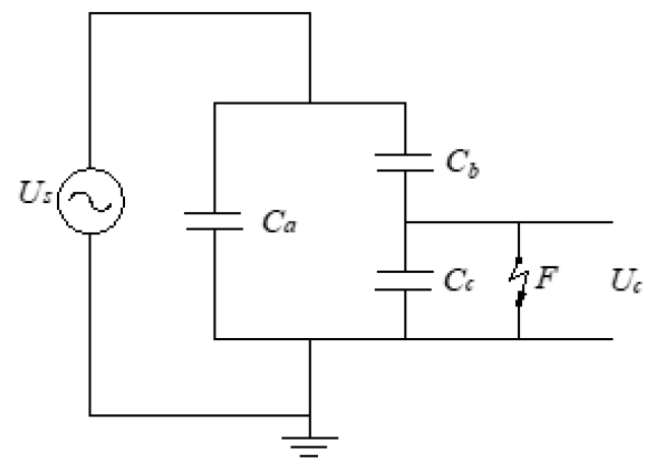

(b)

Figure 3: Partial discharge measuring circuit with capacitance

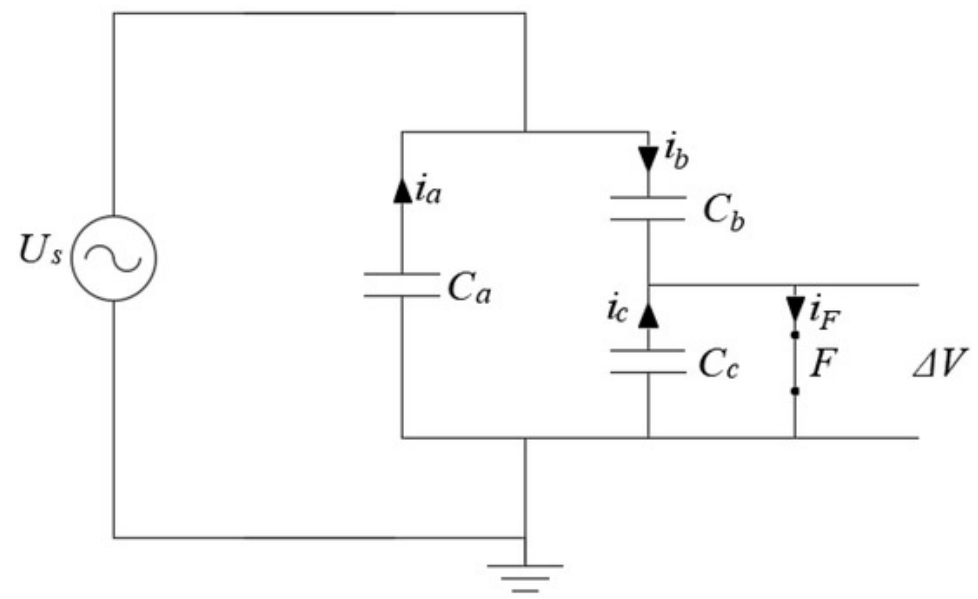

Figure 4: Partial discharge measuring circuit with capacitance and $i_{a}, i_{b}, i_{c}$ and $i_{f}$ 


\section{CONCLUSION}

The breakdowns of electrical equipment occur due to the degradation of the insulating material, the measurement of partial discharges is very necessary for the correct operation of electrical equipment. In high voltage power equipment, insulation failure occurs due to the presence of partial discharges within the sample enclosed in vacuum. For all these reasons, the detection and measurement of partial discharges is necessary for better and reliable operation and increases the useful life of the insulation of high voltage electrical equipment.

\section{SOURCES OF FUNDING}

This research received no specific grant from any funding agency in the public, commercial, or not-for-profit sectors.

\section{CONFLICT OF INTEREST}

The author have declared that no competing interests exist.

\section{ACKNOWLEDGMENT}

None.

\section{REFERENCES}

[1] R. J. Van Brunt, "Physics and Chemistry of partial discharges and corona", IEEE Trans. on dielectric and Electrical Insulation, Vol. 1, No. 5, pp. 761-784, October 1994.

[2] R. Bartnik, "A Comment Concerning the Rise Times of Partial Discharge Pulses”, IEEE Transactions on Dielectrics and Electrical Insulation, Vol.12, No.2, pp.196-202, April 2005

[3] P. W. Karlsson and A. Pedersen, "Partial Discharges in Ellipsoidal and Spherical Voids", IEEE Trans. on Dielectric and Electrical Insulation, Vol. 24, No. 2, pp. 335-342, April 1989

[4] S. Karmakar Number 2, 2011 "Simulation of Partial Discharge in High Voltage Power Equipment" International Journal on Electrical Engineering and Informatics -Volume 3, Number 2, 2011 